\title{
RÉPLICA: CUERPO Y PASIÓN EN DESCARTES (RESPUESTA A JULIANA DA SILVEIRA PINHEIRO)
}

\author{
Pablo E. Pavesi* \\ zppavesi@yahoo.com.ar
}

El objeto de este escrito es el de responder a las críticas que Juliana da Silveira Pinheiro hiciera a mi libro (Pavesi, 2008) en la reseña publicada por Kriterion en junio del año pasado (Pinheiro, 2011). Ensayaremos pues una defensa de nuestra tesis sin renunciar, sin embargo, a otra aspiración más amplia: la de abrir un campo de discusión sobre un texto, Las Pasiones del Alma y un problema muy vigente en los estudios cartesianos actuales, este es: el que se refiere al valor explicativo del cuerpo como causa segunda de las pasiones.

Cabe, en primer lugar, una aclaración que nos permitirá distinguir nuestro objeto de discusión - el cuerpo en Las Pasiones del Alma - de otro, más amplio y ocasional, mi libro. La tesis general de este último es simple: Las Pasiones del Alma (LPA) puede considerarse como una meditación metafísica, esto es, como una investigación sobre un modo del pensamiento, de las verdades que como tal nos permite alcanzar, de los errores a los que nos somete y de los modos en que podemos distinguir las unas de los otros. Una consecuencia negativa de esta tesis - la única que la reseña discute - es que la investigación cartesiana no es, según afirma una interpretación centenaria y vigente, una psicofisiología empírica pues no explica ni pretende explicar la pasión por los movimientos del cuerpo. Esta aclaración me permite recusar una afirmación de mi objetora que creo especialmente injusta. Luego de haber refutado

* Professor de Filosofia da Universidad de Buenos Aires. Réplica recebida em 15/12/2011 e aceita em $3 / 1 / 2012$.

KRITERION, Belo Horizonte, $n^{\circ}$ 125, Jun./2012, p. 317-322. 
una tesis que no es la mía ("a destituição do papel do corpo na investigação das paixões"), Pinheiro escribe que "se esta interpretação se mostra sem fundamento, todo o resto da argumentação, que ele procura deduzir disto também não pode ser sustentada, principalmente, a ideia de que as Paixões da Alma é exclusivamente uma meditação metafísica". Creo que cualquier lector podrá admitir que una investigación dedicada a la noción de unión no substancial, a la dimensión cognitiva y moral de las dos definiciones de pasión, a la originalidad de la definición cartesiana del amor y finalmente, a la definición de la noción de generosidad, entendida como principio de una moral metafísica, esto es, fundada en la idea Dei, no merece ser impugnada masivamente por los resultados de una discusión circunscrita al lugar del cuerpo y especialmente, al valor explicativo de las funciones del cuerpo como causa segunda de pasión.

I. La autora de la reseña critica mi afirmación (Pavesi, 2008, p.66) por la cual, en LPA, "el término corporal ya no significa 'aquello que está compuesto de aquella substancia que llamamos cuerpo', sino: 'todo aquello que puede de cualquier modo afectar el cuerpo" ". No deja de sorprender que para rebatir esta afirmación, la autora repita la cita de Descartes que yo no hago más que traducir. ${ }^{1}$ Queda claro en ese texto que Descartes admite un sentido del término "corporal" que no se refiere a «aquello que está compuesto de aquella substancia que llamamos cuerpo» sino a «todo aquello que puede de cualquier modo [que sea] afectar al cuerpo». Lamentamos que la autora no se detenga ante las dos citas que siguen: a) la carta a Morus, donde Descartes afirma que puede atribuirse la extensión a Dios - no una «extensión de substancia», como pretendía su corresponsal, sino sólo una «extensión en razón de su potencia», esto es, por Su capacidad de mover los cuerpos ${ }^{2}$; b) la carta a Elizabeth donde Descartes ruega a la princesa «de lui attribuer cette matière et cette extension à l'âme» ${ }^{3}$ por su capacidad de mover y ser movida por el cuerpo. Lamentamos además que se desconozca el problema más general (y la tesis más discutible) en el que esas citas se inscriben, a saber, el que resulta de la afirmación de Descartes por la cual la concepción de esa capacidad del alma de ser afectada

1 «Si par corporel, on entend ce qui peut, en quelque manière que ce soit, affecter le corps, l'esprit en ce sens devra aussi être dit corporel; mais, si par corporel on entend ce que est composé de cette substance que s'appelle le corps, ni l'esprit ni même ses accidents... ne doivent point être dits corporels... ", À l'Hyperaspystes, agosto 1641, en Descartes (1996) (en adelante, AT) vol. III, pág. 424, línea 25 - pág. 425, línea 3, nuestro subrayado.

2 «extensum ratione potentiae» AT V, 403, 13. Remitimos al conjunto de citas en Pavesi (2008), p.66, nota 40.

3 AT III, 694, 19-20. 
o afectar los cuerpos es, de hecho, la concepción de la unión, ${ }^{4}$ de manera tal que el alma puede ser considerada unida, con distintos grados de estrechez, a todos los cuerpos que la afectan. Esta concepción no substancial de la unión ya había sido notada en la segunda parte de de Los Principios de la Filosofía y se ratifica, proponemos, en LPA §2, §13, §22, §31 etc. (Pavesi, 2008, pp. 53-58).

II. La segunda objeción se dirige a mi lectura de los artículos $\S 25, \S 26$ y $\$ 27$, donde Descartes define la pasión como el único de los sentimientos «qui se rapportent à l'âme même», a diferencia de todos los otros modos de la sensibilidad «qui se rapportent aux objets qui sont hors de nous, ou... qui se rapportent à quelques parties de notre corps». ${ }^{6}$ En una clara evocación de la Segunda Meditación (que no he sido el primero en notar) Descartes recurre por última vez al argumento del sueño para mostrar que las pasiones son los únicos sentimientos «si proches et si intérieures à notre âme, qu'il est impossible qu'elle les sente sans qu'elles soient veritablement telles qu'elle les sent». ${ }^{7}$ Esta definición distingue a los sentimientos según un criterio puramente fenoménico, relegando la distinción por la causa a un segundo

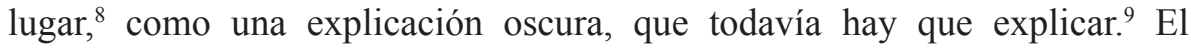
argumento de Pinheiro es el siguiente: "se o critério de "interioridade da alma" fosse suficiente para identificar as paixões da alma e distingui-las dos outros sentimentos, como poderíamos diferenciá-las de outros pensamentos, se não pela característica passiva de ser afetada pelos corpos? Sem a consideração da passividade das paixões, confundiríamos "percepções da alma" com "ações da vontade", que são todos "internos" à alma". La objeción es injusta. Ella desconoce que hemos dedicado un capítulo entero a dilucidar la pasividad propia de la pasión - que la diferencia de los otros sentimientos como de otros modos de constricción -, asunto que comienza en lo que llamamos (no por primera vez) la definición por los efectos, en el artículo $\$ 40$. Brevemente, la pasión tiene como efecto una «disposición a querer» ${ }^{10}$ que no puede constreñir al alma, esencialmente libre por naturaleza, ${ }^{11}$ pero que le impone una respuesta ineludible, a saber, el consentimiento o el no consentimiento de la voluntad

\footnotetext{
4 «...car cela n'est autre chose que la concevoir unie au corps» AT III, 694, 20-21.

5 Principia Philosophiae, II §2, AT VIII-1, 41, 14.-16.

6 Passions de l'âme (en adelante, Passions) artículo §25, AT XI, 348, 3y §26, AT XI 348, 21-23, respectivamente.

7 Passions, §26, AT XI, 348, 25-27.

8 «derechef» Passions, §29, AT XI, 350, 26.

9 «afin d'expliquer leur dernière et plus prochaine cause... » Passions, §29, AT XI, 350, $26-27$.

10 «[les passions]....incitent et disposent leur [les hommes] âme á vouloir...», Passions §40, AT XI, 359, 8-9.

11 Passions, §41, AT XI, 359, 15-16.
} 
al querer que la pasión propone. Es, proponemos, gracias a la interioridad de la pasión que ella puede presentarse como «directamente contraria» a la voluntad - estatuto que ninguno de los otros modos de la sensibilidad puede alcanzar. ${ }^{12}$ La relegación de las funciones del cuerpo como criterio de distinción no implica de ningún modo una "destitução do papel do corpo". Muy por el contrario: hemos dedicado una sección a mostrar que la pasión siempre se conoce como tal, como un pensamiento que es interior al alma, pero que no proviene de ella, sino del cuerpo. Este es el verdadero problema: la pasión inaugura una interioridad recibida. El punto que quisimos destacar es que esta relegación del cuerpo como causa permite una investigación a nuestro parecer más rica, dedicada a los modos en que el cuerpo se siente en la pasión: en su duración, independiente de la acción de los objetos sensibles, en la franca repugnancia, o en una localización difusa, cualitativa, no anatómica, que acompaña a cada pasión simple, excluida la admiración (Pavesi, 2008, pp. $119-123$ y $124-127)$.

III. La tercera crítica se refiere a la «referencia (rapport) al cuerpo» que caracteriza a todos los sentimientos, salvo a la pasión. Citándome mal, Pinheiro alega que por la expresión "sentimientos en el cuerpo" cometo el error de suponer que "que [os] sentimientos são percibidos pelo corpo"-error que quizás deba perdonarse al estudiante todavía confundido por la Segunda Meditación. Debo citar mi libro (p. 86): «La relación (rapport) con el cuerpo no es aquí un juicio, una atribución que desde nuestra infancia confundimos con el sentimiento mismo y por la cual creemos que el sentimiento es en el cuerpo. ${ }^{13}$ Antes que la actividad de un juicio, la relación con el cuerpo indica aquí la característica esencial del sentimiento, el modo en que él se presenta al alma, y por el cual [escribe Descartes] "pensamos ver la antorcha misma y oír la campana..."14». El punto es que, en esos sentimientos, siempre « pensamos ver... y oir...» en un lugar; el sentimiento es, de hecho, un pensamiento ubicado que el alma « piensa ver ante sí (devant soi) o sentir en su cuerpo...»» ${ }^{15}$ Nuestra objetora afirma: "Referir au corpo não significa localizar no corpo”. Pero entonces ¿qué quiere decir que «pensamos ver» en la antorcha o sentir en nuestro cuerpo? "Como distinguir todas essas percepções que estão na alma - pregunta - se não pelos objetos que as causam?” y cita

12 Passions, §47, AT XI, 365, 17-21.

13 Cf. Principia Philosophiae, I §66, AT VIII-1, 32, 14-17; I §67, AT VIII-1, 32, 27-33, 1.

14 Passions, §23, AT XI, 346, 16-20, nuestro subrayado.

15 Passions, §26, AT XI, 349, 2-3. 
el artículo $§ 22$, el cual, justamente, no hace ninguna mención a la causa. La pregunta, agreguemos, confunde nuestro problema, el de las causas segundas, con otro, el de las causas primeras - cuyo examen inicia la segunda parte de LPA. Digamos tan sólo que, apenas comenzado ese examen, Descartes introduce un género de objeto muy particular, la causa libre, ${ }^{16}$ que es sin duda una causa primera pero que no es en absoluto un cuerpo, ni «un objeto que mueve los sentidos», ${ }^{17} \mathrm{y}$ es por definición esencialmente inobjetivable (según argumentamos en pp. 139-146). Más aún, la libertad del agente se erige en criterio de clasificación de segundo orden, reemplazando a los objetos de pasión, ${ }^{18}$ y sirve a Descartes para distinguir entre las especies de la admiración (§55), del amor $(\S 64, \S 83)$, del odio $(\S 65)$, de la tristeza y de la alegría $(\S 66)$.

IV. No necesito detenerme en el último comentario. Según Pinheiro, "Pavesi alega que, no art. $\S 41 \ldots$, Descartes afirma que as paixões estão sob dominio direto e imediato del alma...". No es cierto. Me cito (p. 122): «El artículo $\$ 45 \ldots$ describe por primera vez una acción de la voluntad sobre el cuerpo que es indirecta, en tanto se ejerce por intermedio de una representación que acompaña, por naturaleza o industria, a la pasión que el alma quiere sentir $^{19}$; y que es mediata, en tanto sus efectos no se siguen inmediatamente ${ }^{20}$ de su ejercicio».

V. Respondo finalmente la acusación más grave de todas, esta es: "realizar muitas vezes uma leitura distorcida do texto cartesiano, apresentando citações invertidas (p.ex. p.121 sobre art. 41), alteradas (p.ex. p.60 sobre art. 27) ou que não afirmam o que Pablo diz afirmar (p.ex. p.62 sobre art. 13)". No hay en esas páginas ninguna cita invertida, ni alterada. Que mis citas digan o no aquello que yo afirmo que dicen, es sujeto de discusión. Pasa lo mismo con la bibliografía secundaria: mis citas son correctas. Es cierto que en el amplio estado de la cuestión que sirve de Introducción, la lacónica referencia a Cottingham (Pavesi, 2008, p.47, nota 97) debería haber incluido la distinción entre "trialismo substancial" y "trialismo atributivo". No creo por ello merecer

16 «....d'autres objets, que nous considérons comme des causes libres, capables de faire du bien ou du mal» Passions $§ 55,374,5-7$.

17 Passions §51, AT XI, 372. 5-6.

18 «ll n'est pas besoin aussi de distinguer autant d'espèces d'amour qu'il y a de divers objets qu'on peut aimer» Passions, §82, AT XI, 388, 22-24.

19 «passions que nous voulons avoir » Passions, §45, AT XI, 362, 28.

20 «promptement » Passions, §46, AT XI, 363, 14. 
la ira de la autora, que me acusa del "pouco cuidado que o autor teve com a literatura secundária", de "inventa[r] inimigos" en una vana lucha "contra um moinho de vento".

Las Pasiones del alma están dedicadas a la investigación sobre una verdad referida a los modos en que el bien y el mal se presentan en la pasión; «la force de l'âme ne suffit pas sans la connaissance de la verité». ${ }^{21} \mathrm{Si}$, tal como afirma Pinheiro, "los elementos psicofisiológicos nunca poderão ser negados", cabe preguntar cual es el valor explicativo de esos "elementos", dado que ellos son claramente relegados en la definición de pasión, no sirven a la definición de las seis pasiones simples, ni de sus especies, ni tampoco a la definición de generosidad, pasión siempre virtuosa, que es causada por los mismos movimientos del cuerpo que causan la pasión contraria, el orgullo, siempre vicioso. ${ }^{22}$

\section{Referencias bibliográficas}

Descartes, René: Oeuvres, ed. Adam-Tannery, Paris, Vrin, 11v.

Pavesi, Pablo (2008): La moral metafísica. Pasión y virtud en Descartes, Buenos Aires, Prometeo.

Pinheiro, Juliana da Silveira (2011): "Resenha a Pavesi (2008)", Kriterion, v.52, n.123, pp. 258-263. 